\title{
Why Has the U.S. Beveridge Curve Shifted Back? New Evidence Using Regional Data
}

\author{
Robert G. Valletta \\ Federal Reserve Bank of San Francisco
}

December 2005

Working Paper 2005-25

http://www.frbsf.org/publications/economics/papers/2005/wp05-25bk.pdf

The views in this paper are solely the responsibility of the authors and should not be interpreted as reflecting the views of the Federal Reserve Bank of San Francisco or the Board of Governors of the Federal Reserve System. 


\title{
Why Has the U.S. Beveridge Curve Shifted Back? New Evidence Using Regional Data*
}

\author{
Robert G. Valletta \\ Federal Reserve Bank of San Francisco \\ 101 Market Street \\ San Francisco, CA 94105-1579 \\ Phone: (415) 974-3345 \\ Fax: (415) 977-4084 \\ Email: rob.valletta@,sf.frb.org
}

December 6, 2005

\begin{abstract}
The Beveridge curve depicts the empirical relationship between job vacancies and unemployment, which in turn reflects the underlying efficiency of the job matching process. Previous analyses of the Beveridge curve suggested deterioration in match efficiency during the 1970s and early 1980s, followed by improved match efficiency beginning in the late 1980s. This paper combines aggregate and regional data on job vacancies and unemployment to estimate the U.S. aggregate and regional Beveridge curves, focusing on the period 1976-2005. Using new data on job vacancies from the U.S. Bureau of Labor Statistics, the help-wanted advertising series that formed the basis of past work are modified to form synthetic job vacancy series at the national and regional level. The results suggest that a decline in the dispersion of employment growth across geographic areas contributed to a pronounced inward shift in the Beveridge curve since the late 1980s, reversing the earlier pattern identified by Abraham (1987) and reinforcing findings of favorable labor market trends in the 1990s (e.g., Katz and Krueger 1999).

* The author thanks Geoff MacDonald and especially Jaclyn Hodges for expert research assistance and Ken Goldstein of the Conference Board for providing the help-wanted index data. He also thanks Mark Schweitzer and other participants at the 2004 Federal Reserve System Regional Research meetings for comments. The views expressed in this paper are those of the author and should not be attributed to the Federal Reserve Bank of San Francisco or the Federal Reserve System.
\end{abstract}




\section{Why Has the U.S. Beveridge Curve Shifted Back? \\ New Evidence Using Regional Data}

\section{Introduction}

The Beveridge curve depicts the empirical relationship between job vacancies and unemployment, which in turn reflects the underlying process of job matching between employers and job seekers. In past research, negative co-movements in unemployment and vacancies along a fixed Beveridge curve typically have been associated with cyclical labor market dynamics, whereas shifts in the Beveridge curve- higher or lower unemployment at a given vacancy ratehave been interpreted as reflecting underlying changes in the effectiveness of the job matching process, hence the extent of structural unemployment. Due to the lack of direct data on aggregate job openings over periods of interest, past work mostly has relied on the Conference Board's index of help wanted advertising as a measure of job vacancies (e.g., Abraham 1987, Blanchard and Diamond 1989, Bleakley and Fuhrer 1997). After adjusting this series for apparent secular trends due to factors that are not directly related to aggregate labor market conditions, Abraham (1987) uncovered an outward shift in the Beveridge curve through 1985, which she attributed largely to rising dispersion in regional economic growth that caused a decline in the efficiency of the job matching process. Subsequent research has uncovered inward shifts in the Beveridge curve during the late 1980s through the mid-1990s (Bleakley and Fuhrer 1997), suggesting improved match efficiency during that period.

This paper provides updated estimates of the U.S. Beveridge curve and evidence regarding the role of regional growth dispersion in determining its location, featuring two primary extensions to the existing literature. First, to obtain estimates of the Beveridge curve and its movements, the help-wanted index data that have been the focus of past work are 
adjusted using direct data on job openings from a recently introduced survey from the U.S. Bureau of Labor Statistics (BLS) - the Job Openings and Labor Turnover Survey, or "JOLTS." The JOLTS data are used to form synthetic job opening series over the entire sample period that are largely free of trend biases in the help-wanted index data. Similarly, the unemployment series are adjusted for well-known trends associated with changes in the demographic composition of the labor force (Shimer 1999). Second, this paper exploits the regional component to the U.S. help-wanted index, which is available separately for nine geographic divisions. Although these series are available for a time period similar to that for the national series, to date they have been underexploited in the empirical literature on the U.S. Beveridge curve and the job matching process. Like the national series, the divisional help-wanted series are converted to synthetic job opening series using the JOLTS data.

Following background discussion in Section II and description of the adjusted job openings and unemployment series in Section III, Section IV of the paper presents regression results. The analyses reveal an inward shift in the U.S. Beveridge curve locus since 1985. Additional analyses with the divisional data provide a simple answer to the paper's title question: the U.S. Beveridge has shifted back because the impact of rising regional dispersion in the earlier outward shift identified by Abraham (1987) has been reversed. Although the precise empirical representation of the Beveridge curve used here is judgmental, the key contribution of declining regional dispersion is robust to alternative representations. As discussed in the concluding section, these findings reinforce existing depictions of improved performance of the U.S. aggregate labor market in the 1990s (e.g., Katz and Krueger 1999) and beyond. 


\section{The Beveridge Curve}

The Beveridge curve depicts a negative short-term relationship between unemployment and vacancies, which may shift over time (see Figure 1 for a plot of the empirical Beveridge curve in the U.S., discussed further below). A substantial body of research has focused on the role of the Beveridge curve in Phillips curve models of aggregate fluctuations (originating with Hansen 1970). More recently, the Beveridge curve concept has been used to test the empirical implications of alternative business cycle models for the impact of aggregate shocks on labor market outcomes (Shimer 2005).

The aggregate Beveridge curve is best understood in the context of a search and matching model of labor market operations. ${ }^{1}$ In such a model, the rate of job matching or hiring, $m$, can be expressed as a function of the unemployment rate, $u$, the job opening (vacancy) rate, $v$, and a set of other, possibly unobserved influences on the matching process, denoted by z:

$$
m=m(u, v, z) \text {, where } m_{u}>0 \text { and } m_{v}>0
$$

In a labor market steady state, the rate of job matching $m$ equals a fixed rate of job separations $s$. The resulting equality is:

$$
m(u, v, z)=s
$$

\footnotetext{
${ }^{1}$ See Petrongolo and Pissarides (2001) for an overview of the job matching function and its relation to the Beveridge curve. Direct estimation of the matching function requires data on flows into employment (see e.g. Blanchard and Diamond 1989, Bleakley and Fuhrer 1997, Anderson and Burgess 2000).
} 
Given that $s$ is a constant, this expression implicitly defines a negative steady-state relationship between the unemployment rate and the vacancy rate. The exact derivation often relies on constant returns to scale in the matching function, which implies a Beveridge curve that is convex to the origin in $u-v$ space. $^{2}$ The presence of factors embodied in $z$ implies that the location of the Beveridge curve in $u-v$ space may change over time. In particular, movements away from the origin — which imply higher unemployment associated with a given level of vacancies - imply a decline in the efficiency of the job matching process.

Since the early 1980s, analysis of the Beveridge curve has largely focused on its use as means for distinguishing between cyclical and structural unemployment. In this research, movements along a fixed, convex Beveridge curve are associated with cyclical shocks, while shifts in the Beveridge curve-positive co-movements in unemployment and vacancies-are associated with changes in latent parameters that alter the efficiency of the job matching process (e.g., changing demographics, shifts in the geographic or industry locus of job growth, etc.). This depiction of cyclical movements along a fixed Beveridge curve has been recognized as overly simplified. For example, under the reasonable assumption that vacancies adjust to shocks more quickly than does unemployment, the return to an initial Beveridge curve equilibrium after a cyclical shock will follow a counterclockwise loop, with vacancies adjusting upwards more quickly than unemployment falls (Bowden 1980, Blanchard and Diamond 1989). Such adjustments should be relatively short lived, however, occurring at business cycle frequencies, as distinct from longer term shifts in the position of the Beveridge curve that suggest persistent, structural shifts in match efficiency.

\footnotetext{
${ }^{2}$ As Petrongolo and Pissarides (2001) note, empirical evidence using data for various countries appears largely consistent with the simple two-factor matching function with constant returns, although the (continued)
} 
After adjusting her measure of vacancies for underlying influences that are unrelated to aggregate labor market conditions, Abraham (1987) found a relatively persistent and sizable outward shift in the U.S. Beveridge curve between the 1950s and early 1980s. Her empirical analyses suggested that this shift was largely due to rising disparities in regional economic conditions. This finding was indirectly confirmed by Blanchard and Diamond (1989), who embedded Abraham's adjusted help-wanted index in a more general empirical model of labor market dynamics. By contrast, analyses of the Beveridge curve relationship in Germany (Börsch-Supan 1991) and Great Britain (Jackman and Roper 1987, Wall and Zoega 2002) suggest a limited role for rising regional disparities as an explanation for substantial outward shifts found in those countries. Moreover, these authors interpret their evidence as indicating the limitations of empirical Beveridge curves for distinguishing between cyclical and structural fluctuations, due to the potential similarities between these movements for plausible types of cyclical shocks (see in particular section IV of Börsch-Supan 1991). ${ }^{3}$ In what follows, I show that with proper data adjustments, one can obtain precise estimates of the U.S. aggregate and regional Beveridge curves, which exhibit plausible cyclical and secular patterns based on underlying theory and past empirical findings.

\section{Adjusting the Vacancy and Unemployment Series}

Because there is no continuous aggregate vacancy series in the United States, the literature on the U.S. Beveridge curve has largely relied on the help-wanted advertising index to measure changes in job vacancies over time. The Conference Board, a non-profit business

alternatives have not been tested in detail. They also note that constant returns are not essential for the derivation of a Beveridge curve relationship as in equation (2). 
research organization headquartered in New York City, produces these data, which are described in detail in Abraham (1987). Briefly, the help-wanted index is based on counts of help-wanted advertisements appearing in the classified section of a major newspaper in each of 51 cities nationwide. After the application of several normalizing adjustments, the data by city are aggregated to provide help-wanted index series for nine major regions and the United States as a whole.

To measure unemployment, I start with the official national unemployment rate, calculated monthly by the U.S. Bureau of Labor Statistics (BLS). Corresponding figures for the nine major regions are formed using the underlying labor force and unemployment figures at the state level. The labor force and payroll employment data needed to form the complete regional unemployment and vacancy series are only available back to 1976, which limits the regional analyses to the time period 1976-2005. For the analyses below, the underlying monthly data are expressed in the form of quarterly averages, which are aggregated up to yearly averages for display purposes in some cases. Figures for 2005 are based on data through the first two quarters of the year. All of the data used in this paper are seasonally adjusted.

The resulting plot of the Beveridge curve is displayed in Figure 1. Following past practice, I display the "normalized" help-wanted index, for which the help-wanted index is divided by nonfarm employment in millions to adjust for general growth in labor demand. ${ }^{4}$ This chart suggests significant changes in the efficiency of the aggregate job matching process in the United States over the past four decades, including reduced efficiency implied by the

\footnotetext{
3 This concern about using the Beveridge curve to distinguish between cyclical and structural shocks also is evident in the Brookings panel discussion of Blanchard and Diamond (1989).

${ }^{4}$ These data largely represent a continuation of the series used by Abraham (1987) in her Figure 1, except for a renormalization of the help-wanted index in 1987 that uniformly reduced its magnitude.
} 
outward movement in the 1970s and early 1980s (identified by Abraham) followed by increased efficiency implied by inward movement in the late 1980s and late 1990s. ${ }^{5}$

Abraham (1987) and subsequent authors have argued that the plot of the normalized helpwanted and unemployment series in Figure 1 does not provide an unbiased representation of cyclical and structural movements in the $u-v$ locus. In particular, Abraham pointed to the impact on help-wanted advertising of secular changes in factors that are not directly related to the job matching process. These factors include changes in the occupational composition of employment (towards white-collar jobs that are more likely to be advertised), increased job advertising linked to equal employment opportunity pressures, and consolidation in newspaper markets, each of which contributed to an upward drift in the help-wanted index. After directly adjusting the help-wanted index to eliminate this extraneous upward drift, Abraham still found evidence for significant outward shifts in the Beveridge curve during her sample period. Subsequent work using the help-wanted index has relied on Abraham's adjustments to provide an accurate measure of vacancies over time, extending her adjustments forward using a flexible parametric form (Blanchard and Diamond 1989, Bleakley and Fuhrer 1997).

In more recent work, Zagorsky (1998) extended the help-wanted series back to 1923 and argued that it exhibits no significant secular biases through 1994. In particular, Zagorsky compared the vacancy rate implied by the help-wanted index with direct measurement of new hiring and vacancies and found very little evidence of secular trends in the vacancy series (relative to labor market conditions) over his entire sample frame. He also re-examined the biases generated by occupational shifts, anti-discrimination laws, and newspaper consolidation. He found that applying his modified correction factors based on these developments had very

\footnotetext{
${ }^{5}$ Data for the 1950s are available but excluded from the chart for visual clarity. The u-v locus for the (continued)
} 
little impact on vacancy rate estimates derived from the help-wanted index, implying limited trend biases in the normalized help-wanted index.

Trends in the help-wanted index that are relevant to the sample period used in this paper are displayed in Figure 2. This plot depicts the normalized help-wanted index for the period 1960-2005 and its trends estimated over the complete period and the sub-period on which this paper focuses (1976-2005). The trend lines were estimated using a Hodrick-Prescott (HP) filter. ${ }^{6}$ A slight upward trend is evident in the 1960 s, followed by a largely flat segment through the mid- to late 1980s and a downward trend subsequently. Given the findings of Zagorsky, it appears likely that any trends prior to 1994 reflect labor market conditions rather than unrelated secular changes in the volume of job advertising. However, the significant downward drift that is evident beginning in the 1990 s is another matter. It is likely that recent factors such as growing reliance on alternative sources of job search, such as the Internet, have substantially reduced employers' reliance on traditional help-wanted advertising. Clearer identification of this trend requires comparing the help-wanted series to an independent measure of job vacancies.

Fortunately, relatively new data are available to serve the dual purpose of pinning down the recent secular trend in help-wanted advertising and also translating the help-wanted series into a job vacancy series: the monthly "Job Openings and Labor Turnover Survey" (JOLTS) conducted by the U.S. BLS beginning in December 2000. The JOLTS survey is administered to a representative sample of about 16,000 establishments nationwide and provides data on job openings as well as hires and separations. The definition of a job opening (vacancy) is quite

1950s lies to the left and below that for the 1960s.

${ }^{6}$ Experimentation with alternative degrees of smoothing led to use of an HP smoothing parameter of $10^{5}$ for the quarterly series used in this paper. This follows Shimer (2005), who used detrended help-wanted and unemployment series in his analyses of cyclical Beveridge Curve movements. My focus on secular (continued) 
precise, reflecting that: (1) a specific position exists; (2) work could start within 30 days; (3) the employer is actively recruiting from outside the establishment that has the opening. All types of openings are surveyed, including part-time and temporary jobs. In addition to the national series, the data are available for four broad regions. The job opening (vacancy) rate is defined as the ratio of the number of job openings to the sum of employment and job openings. ${ }^{7}$

The JOLTS series only became available in December 2000, near the peak of the last expansion, which limits its direct use for Beveridge curve estimation. However, its movements since then provide useful information for assessing trends in the help-wanted series and also for translating the latter into a job vacancy series. To do so, I began by running OLS regressions of the JOLTS vacancy rate series on the normalized help-wanted series, a linear time trend, and a constant; this equation was estimated using quarterly data for the period 2001Q1-2005Q2, separately for the U.S. and the four broad regions available in the JOLTS data. ${ }^{8}$ The normalized help-wanted series at the regional level were formed by aggregating up the underlying divisional series using nonfarm payroll employment weights. Table 1 displays the results of these regressions. In each case there is a quantitatively and statistically significant time trend, which reflects downward drift in the help-wanted series relative to the JOLTS vacancy rate series. ${ }^{9}$

The time trend can be seen more clearly in Figure 3, which displays monthly values of the JOLTS vacancy rate series, the normalized help-wanted index series, and a synthetic vacancy rate series that is formed as the fitted values from the regressions in Table 1; the series are

shifts in the Beveridge Curve requires a different approach to adjusting the help-wanted series, as described in the text.

${ }^{7}$ I use the seasonally adjusted series. JOLTS survey information is available online at http://www.bls.gov/jit/home.htm.

${ }^{8}$ Rather than taking the initial monthly value of the JOLTS in December 2000 as representing a complete quarterly value, I eliminated that observation to reduce resulting measurement error.

${ }^{9}$ Higher order terms in the time trend (such as a quadratic) did not improve the fit of these equations. 
normalized so that their means equal 100 in 2001Q1 (for direct visual comparison, the helpwanted series is normalized to equal the synthetic opening series in 2001Q1). At the national level (panel A), the synthetic vacancy rate series closely tracks the JOLTS vacancy series. By contrast, the downward trend in the unadjusted help-wanted series causes it to lie well below the JOLTS series. Panels B-E indicate that the quarterly co-movement generally is less precise at the regional level than at the national level, due in part to higher volatility in the JOLTS series (especially in the West region). However, the adjustment for the downward drift in the helpwanted index is critical in all cases. This evidence suggests that the synthetic vacancy rate series estimated from the help-wanted index provides a reasonably accurate measure of actual job vacancies.

Given these findings, I take the following approach to adjusting the help-wanted index series over my complete sample frame. I use fitted values from the trend-adjusted regressions reported in Table 1 to translate the help-wanted series into synthetic vacancy rate series back to the first quarter of 1993. Zagorsky's (1998) finding of minimal trend biases in the normalized help-wanted series through 1994 suggests that 1995 or a later year should be chosen for the cutoff on the trend adjustment. However, Figure 2 suggests that a downward trend in the normalized help-wanted index appeared prior to 1994. Moreover, experimentation revealed that 1993 cutoff produced the most plausible range of values for the synthetic vacancy rate series at the national and divisional level. ${ }^{10}$ I eliminated the trend adjustment for all observations prior to 1993Q1 by fixing the trend adjustment at its 1993Q1 value for all pre-1993 observations and then combining it with the level adjustment implied by the coefficient on the help-wanted index

\footnotetext{
${ }^{10}$ When 1990 was used as the cutoff for the trend adjustment, negative values for the synthetic vacancy rate series were obtained for the New England division in 1990-91. Using a later cutoff, such as 1995, produced implausibly high values of aggregate vacancies over my sample frame.
} 
and the regression constant. This is done for the national and divisional help-wanted series, using the regression results from the regional regressions to fit values for each underlying geographic division. $^{11}$

The U.S. synthetic vacancy rate series formed from this procedure is displayed in Figure 4, along with its HP trend line, which is relatively flat over my primary sample frame (19762005). This series ranges in value from a low of 1.84 percent in 1991Q4 to a high of 3.93 percent in 2000Q1. My procedure yields higher vacancy rates than those produced in past research, such as Zagorsky (1998); this is largely explained by the difference in levels between the JOLTS and the vacancy series used in past work. My approach to forming a synthetic vacancy rate series ignores any upward or downward secular drift in the normalized help-wanted series prior to 1993, but the evidence discussed above suggests that such trends are small to nonexistent, especially over my sample frame.

Like the help-wanted index that was used to measure job vacancies, the unemployment rate at the national and regional levels also has been trending over time. As discussed by Shimer (1999), the changing age structure of the population has exerted substantial influence. This can be seen in the first panel of Figure 5, which displays the official BLS unemployment rate over the period 1960-2005Q2 and its HP filtered trends over the complete sample period and the subperiod on which this paper focuses (1976-2005); the trend unemployment rate increased substantially as the labor force share of teenagers grew (1970s) and declined as the share of teenagers fell back (1980s and 1990s) While variation in unemployment rates due to changing age structure may reflect changes in the job matching process, they do not reflect underlying

\footnotetext{
${ }^{11}$ Prior to these adjustments, I multiplied the normalized help-wanted series for regions and divisions by the ratio of the national mean to their mean, so that each series is measured on the same basis.
} 
changes in aggregate match efficiency that typically are thought of as shifting the position of the Beveridge curve.

To adjust for the influence of changing age structure on the unemployment rate, I follow Shimer (1999) in forming a counterfactual "age-adjusted" unemployment rate, which equals the unemployment rate calculated by holding the labor force shares of seven age groups at base-year values but allowing the group-specific unemployment rates to change as observed in the data; the base year used here is 1978, which Shimer identified as the demographically "worst" year with respect to high unemployment rates during the post-war period. ${ }^{12}$ The resulting series is displayed in the second panel of Figure 5. The age adjustment substantially reduces the amplitude of long-run variation in the unemployment rate: between Panels A and B of Figure 3, the spread between the maximum and minimum values of the HP trend line is reduced by about 1.5 percentage points between the late 1960 s to early 1980 s and the early 1980 s to early 2000 s. I use the age-adjusted series as my primary measure of the unemployment rate but also assess below how much difference the age adjustment makes for the sources of estimated movements in the Beveridge curve.

Figure 6 displays the U.S. Beveridge curves based on the synthetic vacancy rate series and age-adjusted unemployment rate for the period 1960-2005. Like Figure 1, the Beveridge curves in this figure exhibit the expected counter-clockwise adjustment pattern around recessions (e.g., 1981-1982 and 1990-1991), as vacancies rise more quickly than unemployment falls during the recovery phase. The outward shift in the Beveridge curve from the 1960 s to the early 1980 s, as identified by Abraham (1987), is clearly evident, as is a substantial inward shift during the late

12 The age groups used are 16-19, 20-24, 25-34, 35-44, 45-54, 55-64, and 65+. As Shimer (1999) notes, other demographic changes, notably rising labor force shares for women, had very little impact on the aggregate unemployment rate; I therefore adjust for age only. 
1980s. However, the magnitude of the inward shift in the 1990s is much smaller in this figure than it is in Figure 1. This occurs for two reasons: (i) the trend adjustment applied to the synthetic vacancy rate series from 1993-2005 reduces the decline in vacancies implied by movements in the unadjusted help-wanted series during the 1990s; and (ii) the age adjustment applied to the unemployment rate shrinks the reduction in the unemployment rate that occurred in the 1990s. Nevertheless, the position of the Beveridge curve for the years 2000-2005, which is interior to most other sets of years, suggests higher match efficiency and more favorable labor market conditions than any period since the 1960s.

\section{Cyclical and Secular Movements in the Beveridge Curve}

\section{A. Estimation}

Following the visual assessment presented in the preceding section, more precise measurement of cyclical and structural changes in the U.S. and regional Beveridge curves can be obtained by estimating the following equation using OLS:

$$
u_{t}=\alpha+\beta_{1} v_{t}+\beta_{2} v_{t}^{2}+\tau Y+\varepsilon_{t}
$$

Equation (3) is estimated separately on the U.S. aggregate data and on data for each of the nine underlying geographic divisions for which the help-wanted series is available, for quarterly data spanning the period 1976Q1 through 2005Q2 (indexed in the equation by $t$ ). In this equation, $u$ is the unemployment rate, $v$ is the synthetic vacancy rate series described in the previous section, $Y$ represents time effects (which are captured by a complete set of year dummies), and the remaining symbols are parameters to be estimated (including a vector of 
coefficients $\tau$ on the year dummies). This specification enables estimation of movements along the Beveridge curve locus at a quarterly frequency and longer term shifts in match efficiency reflected in changing values of the year dummies (also represented by $z$ in equations 1 and 2). ${ }^{13}$ The inclusion of the quadratic term in the vacancy rate is consistent with convexity of the Beveridge curve, as discussed earlier (Section II). ${ }^{14}$

Table 2 presents the results of estimating equation (3) using the synthetic vacancy and age-adjusted unemployment series (as displayed for the U.S. in Figure 6). The results for the U.S. are listed in the first column and the results for the nine divisions are listed in columns 3-11 (column 2 is discussed in the next sub-section). The regression results reveal a strong negative relationship between the unemployment and vacancy rates in all cases, which is large and precisely estimated. The coefficient on the quadratic term in the vacancy rate is positive and statistically significant in all cases except for the Pacific division in column 11, implying that the Beveridge curves in general are convex. In particular, based on the column 1 results, a one percentage point increase in the national vacancy rate above its sample mean (2.9 percent) is associated with a 1.6 percentage point decline in the unemployment rate; near the national sample maximum value of vacancies ( 3.9 percent), the same increase in vacancies is associated with a 0.5 percentage point decline in the unemployment rate.

\footnotetext{
${ }^{13}$ The quarterly frequency enables the use of year dummies to summarize time effects (see Figure 7 below) rather than the linear trend coefficient that is typically employed in studies that rely on annual data. While the underlying unemployment and vacancy series used here are available at a monthly frequency, the quarterly frequency is more commonly used for the analysis of macroeconomic aggregates, and preliminary estimates indicated that use of the monthly frequency does not improve the precision of the estimates.

${ }^{14}$ A constant returns technology for the job matching function leads naturally to a log-linear empirical specification for Beveridge curve estimation. The equations here are estimated in levels with a quadratic (continued)
} 


\section{B. Secular Shifts and Regional Dispersion}

Secular shifts in the location of the cyclical Beveridge curves are reflected in the coefficients on the year dummies from the regressions reported in Table 2. These coefficients, which are displayed in Figure 7, represent the cumulative shift in the position of the Beveridge curve relative to the omitted base year (1976 for all regressions reported here); the coefficients quantify shifts in the position of the Beveridge curve as percentage-point changes in the unemployment rate at a fixed vacancy rate. The year dummies from the equation estimated on national data (column 1 of Table 2) are labeled "Total shift." A cyclical pattern is evident in the yearly movements: the national Beveridge curve shifts out in the aftermath of recessions, reflecting the counter-clockwise movement evident in Figure 6, and shifts back in as the recovery proceeds. However, a long-term inward shift is evident as well, with the unemployment rate associated with a fixed cyclical Beveridge curve declining by about $1 \frac{1}{2}$ to 2 percentage points between the late 1970s and early 2000s. ${ }^{15}$

Following Abraham (1987) and subsequent authors, the contribution of regional dispersion to shifts in the Beveridge curve can be assessed by comparing the time effects from the U.S. national regression in column 1 with the average time effects from the divisional regressions in columns 3-11. ${ }^{16}$ In particular, the contribution of regional dispersion is reflected in the extent to which the yearly shifts obtained from the U.S. national equation exceed the

term in order to quantify the slope and position of the estimated Beveridge curves and to highlight their underlying convexity.

${ }^{15}$ The quarterly data needed to extend my empirical framework back before 1976 are not available. However, using yearly data, I confirmed the results of Abraham (1987) regarding shifts in the Beveridge curve and the role of regional dispersion for the years 1960-1985; these results are available on request. ${ }^{16}$ Abraham's regional results were based on data for 24 states; Figure 8, discussed below, provides some comparison of relevant patterns found in the division and state data. 
average yearly shifts at the divisional level. ${ }^{17}$ The latter are obtained as the weighted sum of the coefficients from the separate divisional regressions in columns 3-11 of Table 2, using the divisions' shares of national payroll employment as the weights; in Figure 7, the corresponding plot line is labeled "Shift w/o reg. div.",18

Abraham found that rising dispersion of regional growth accounted for an increase in unemployment of about 1.4 percentage points between 1970 and 1985. Figure 7 displays the impact of regional dispersion as the difference between the plots showing the total shift and the shift with the influence of regional dispersion removed. Some impact of regional dispersion is evident during the years 1977-1981 (near the end of Abraham's sample frame) and beginning in 1994 through the end of the 1990s expansion. However, the offset to the net decline in the unemployment rate due to regional dispersion is never more than 0.45 percentage points over my sample frame, and for most years it is quite close to zero (the exact series values displayed in Figure 7 are listed in Appendix Table 1). This finding is not sensitive to the exact representation of the Beveridge curve used here. In particular, Appendix Table 2 and the corresponding Appendix Figure 1 parallel Table 2 and Figure 7 in the text, except these appendix displays rely on the unadjusted help-wanted and unemployment data that were used to produce Figure 1 in the text. Although the magnitude of the Beveridge curve shifts is different across the two representations, due to the different parameterization of the vacancy rate and the absence of trend

\footnotetext{
${ }^{17}$ As discussed by Abraham (1987), the contribution of regional dispersion to Beveridge curve shifts can arise due to convexity in the empirical Beveridge curve or lagged adjustments to unequal labor demand shocks across regions.

${ }^{18}$ The coefficients on the vacancy rate and its squared term for the weighted results in column 2 are somewhat smaller than the corresponding national coefficients from column 1, implying a more limited response of the unemployment rate to vacancies at the division level (on average) than at the national level.
} 
adjustments in the Figure 1 data, the appendix results also reveal little to no impact of regional dispersion on Beveridge curve movements between 1976 and 2005.

Figure 8 reveals why the impact of regional dispersion identified by Abraham is not reproduced over my sample frame. The figure displays the dispersion of yearly employment growth across geographic divisions, measured essentially as a weighted standard deviation. ${ }^{19}$ In addition to the dispersion series calculated at the division level, Figure 8 also displays the same series calculated across the 50 states plus the District of Columbia (as used by Abraham; her series is essentially replicated here for the years 1961-1985, except for the influence of minor data revisions). Comparison of the two plots indicates a very close correspondence, suggesting that my findings are not an artifact of the use of division data rather than state data. Both series show a marked increase from the late 1960s up to about 1980, to which Abraham largely attributed outward shifts in the Beveridge curve during her sample frame. Since the early 1980s, however, regional growth dispersion has trended downwards. ${ }^{20}$ The average value of the dispersion measure for geographic divisions increased from 0.93 in the 1960 s to 1.60 in the 1970s and then fell back to 0.96 in the 1990s and 0.61 from 2000 through 2004. Although state and division unemployment data are not available on a consistent basis before and after 1976, regional dispersion in unemployment rates has exhibited a pattern similar to that in employment

${ }^{19}$ Following Abraham (1987), the formula for the dispersion measure is:

$$
d_{t}=\sqrt{\sum_{i=1}^{K} \frac{E_{i t}}{E_{t}}\left(g_{i t}-g_{t}\right)^{2}}
$$

where $d_{t}$ is dispersion in year $t$ across $K$ geographic areas, $E_{i t}$ and $E_{t}$ represent employment levels in each geographic area and the nation, and $g_{i t}$ and $g_{t}$ represent employment growth relative to the previous year in each geographic area and the nation. 
growth since 1960. Declining regional dispersion also is reflected in the pattern in job vacancies. In particular, wide variation in job vacancy rates across geographic divisions was evident in the 1970s and early 1980s, with relatively low vacancy rates in the eastern portion of the country and high vacancy rates in the western portion, followed by substantial convergence in the 1990s and early 2000 s. $^{21}$

On net, the magnitude of the Beveridge curve shifts and changes in regional growth dispersion are mutually consistent over the period 1970-2005. In particular, Abraham found that about 1.4 percentage points of the 1.8 percentage-point increase in the unemployment rate associated with Beveridge curve shifts between 1970 and 1985 was due to rising geographic dispersion of employment growth. By contrast, I find that geographic growth dispersion fell below its 1960s levels by the early 2000s, reversing the pattern identified by Abraham. The result was a $1 \frac{1}{2}$ to 2 percentage-point decline in the unemployment rate associated with Beveridge curve shifts between the late 1970s and early 2000s, producing a Beveridge curve that is interior to any observed since the 1960 s.

\footnotetext{
${ }^{20}$ Of note, in contrast to past recessions the degree of regional dispersion increased only slightly during the 2001 recession.

${ }^{21}$ Results regarding geographic dispersion in unemployment and vacancy rates are available on request.
} 


\section{Conclusions}

Combining direct data on job vacancies from a new BLS data program ("JOLTS") with the help-wanted series used in past research, this paper has examined movements in the unemployment-vacancy relationship embodied in the Beveridge curve. The series are adjusted for secular trends in job advertising and the age structure of the labor force that are unrelated to the underlying effectiveness of the aggregate job matching process. The adjusted data produce relatively precise and plausible estimates of the Beveridge curve relationship for the U.S. and its nine geographic divisions. A pronounced inward shift in the position of the Beveridge curve has been evident since the late 1970s or early 1980s, reversing the earlier pattern identified by Abraham (1987) and implying increased efficiency for the aggregate job matching process. My complete results suggest a simple explanation for this finding: the process identified by Abraham (1987), whereby increasing dispersion of labor demand growth across geographic areas caused the Beveridge curve to shift out, has been reversed, causing the Beveridge curve to shift back in. Indeed, after noting declining dispersion of employment growth across states at the end of her sample period (1984-1985), Abraham argued that if declining dispersion in those years represented the start of a trend, "insofar as dispersion in employment growth rates across states has indeed been responsible for the outward shift in the aggregate [Beveridge curve], that curve should now begin to shift inwards" (p. 240). Her prediction has been born out.

More generally, my finding of inward shifts in the Beveridge curve over the past two decades reinforce Katz and Krueger's (1999) conclusions regarding improved U.S. labor market performance in the 1990s. The inward shift in the Beveridge curve may underlie the more favorable Phillips curve tradeoff between unemployment and wages that has been estimated for the 1990s (Katz and Krueger 1999). Indeed, this interpretation of the shifting Beveridge curve 
was emphasized in Dickens' (1999) comments on Katz and Krueger. Moreover, I find that these favorable trends have continued through the first two quarters of 2005. Despite Blanchard and Diamond's (1989) admonition that the Beveridge curve has wrongly played "second fiddle" to the Phillips curve in research on aggregate labor market dynamics, only limited subsequent research has been conducted regarding movements in the U.S. Beveridge curve. My findings of substantial and ongoing shifts in the Beveridge curve suggest that it may merit renewed attention. 


\section{$\underline{\text { References }}$}

Abraham, Katharine G. 1987. "Help-Wanted Advertising, Job Vacancies, and Unemployment." Brookings Papers on Economic Activity 1: 207-248.

Anderson, Patricia M., and Simon M. Burgess. 2000. "Empirical Matching Functions: Estimation and Interpretation Using State-Level Data." Review of Economics and Statistics 82(1): 93-102.

Blanchard, Olivier, and Peter Diamond. 1989. "The Beveridge Curve." Brookings Papers on Economic Activity 1: 1-76.

Bleakley, Hoyt, and Jeffrey C. Fuhrer. 1997. "Shifts in the Beveridge Curve, Job Matching, and Labor Market Dynamics.” New England Economic Review Sept./Oct.: 3-19.

Börsch-Supan, Axel H. 1991. "Panel Data Analysis of the Beveridge Curve: Is There a Macroeconomic Relation between the Rate of Unemployment and the Vacancy Rate?" Economica 58: 279-297.

Bowden, Robert J. 1980. "On the Existence and Secular Stability of $u-v$ Loci." Economica 47 (Feb.): 33-50.

Dickens, William T. 1999. Comments and discussion for "The High-Pressure U.S. Labor Market of the 1990s", by Lawrence F. Katz and Alan Krueger. Brookings Papers on Economic Activity 1: 72-79.

Hansen, Bent. 1970. “Excess Demand, Unemployment, Vacancies, and Wages.” Quarterly Journal of Economics 84 (Feb.): 1-23.

Jackman, Richard A., and Stephen Roper. 1987. "Structural Unemployment." Oxford Bulletin of Economics and Statistics 49(1): 9-36.

Katz, Lawrence F., and Alan Krueger. 1999. “The High-Pressure U.S. Labor Market of the 1990s.” Brookings Papers on Economic Activity 1: pp. 1-65.

Petrongolo, Barbara, and Christopher A. Pissarides. 2001. "Looking into the Black Box: A Survey of the Matching Function." Journal of Economic Literature 39(2, June): 390431.

Shimer, Robert. 1999. "Why Is the U.S. Unemployment Rate So Much Lower?" In Ben S. Bernanke and Julio J. Rotemberg, eds., NBER Macroeconomics Annual 1998, pp. 11-61. Cambridge: MIT Press.

Shimer, Robert. 2005. "The Cyclical Behavior of Equilibrium Unemployment and Vacancies." American Economic Review 95(1): 25-49. 
Wall, Howard J., and Gylfi Zoega. 2002. "The British Beveridge curve: A tale of ten regions." Oxford Bulletin of Economics and Statistics 64(3): 257-276. 
Figure 1: U.S. Beveridge Curve, 1960-2005

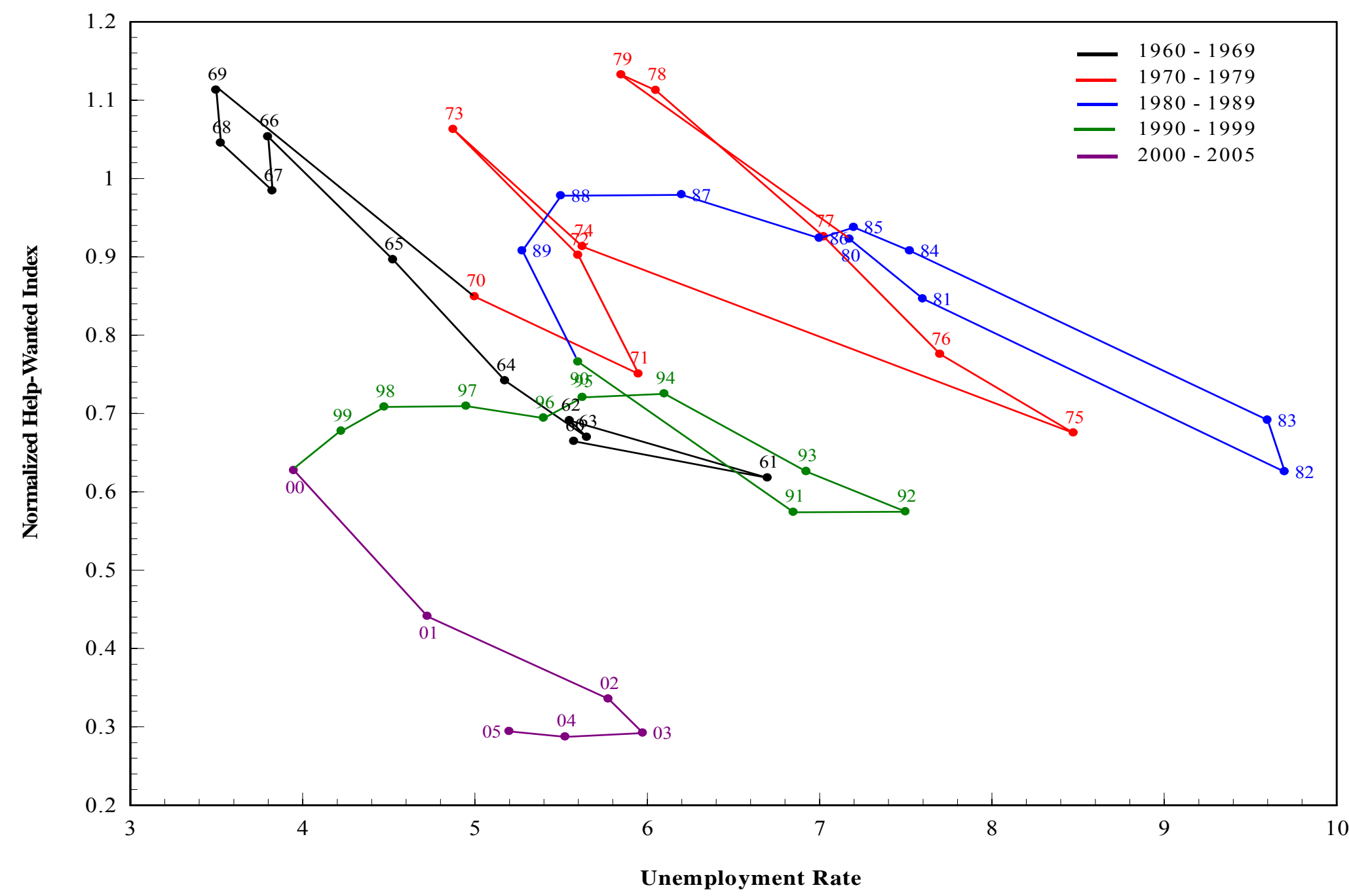

Note: Help-wanted index data are from the Conference Board, index $=100$ in 1987; the normalized series is divided by nonfarm payroll employment in millions. Unemployment data are from the U.S. Bureau of Labor Statistics (BLS). Data for 2005 are through Q2. The underlying data are seasonally adjusted. 
Figure 2: Trends in the U.S. Normalized Help-Wanted Index (HWI), 1960-2005(quarterly data)

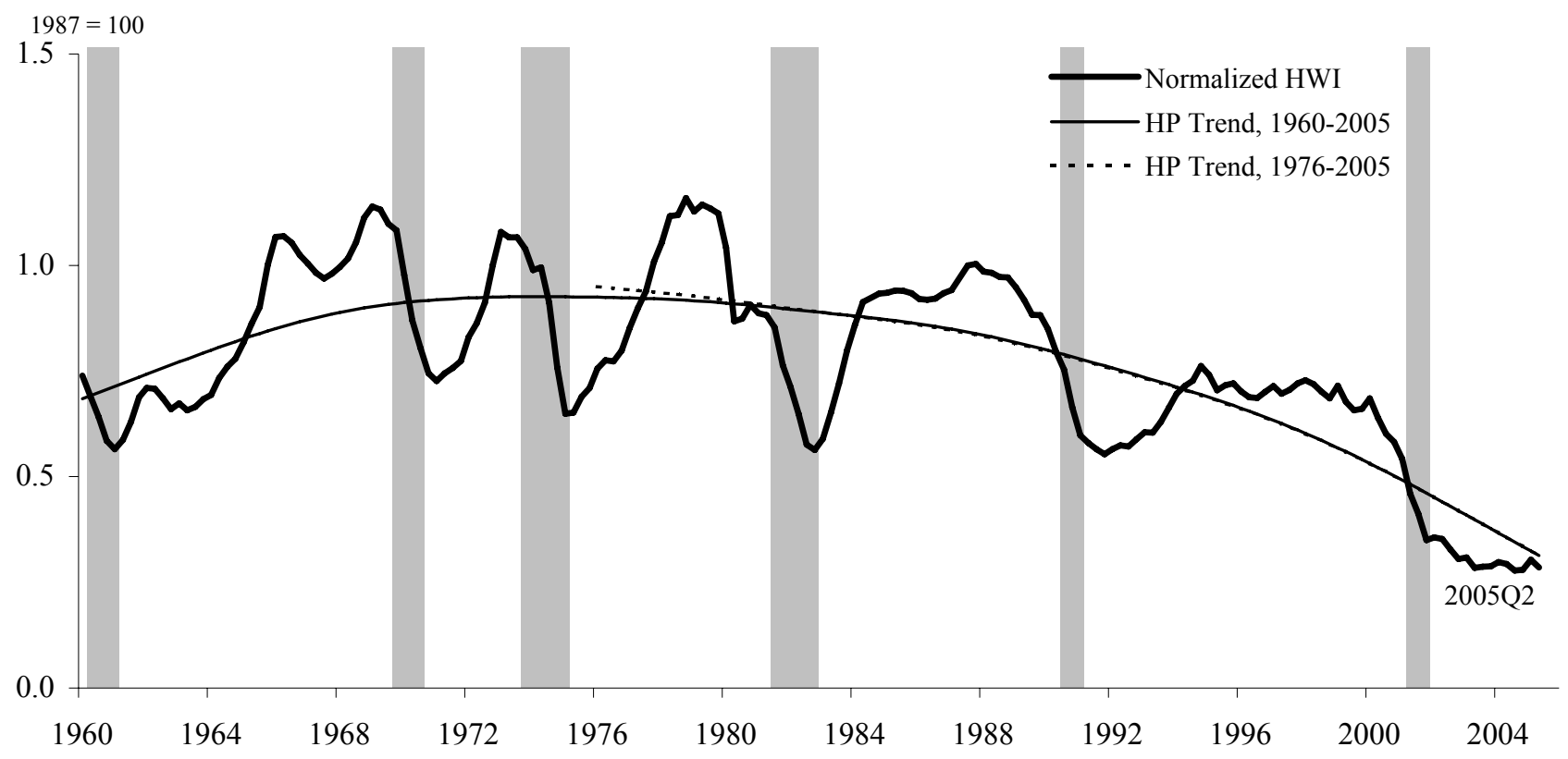

Trend estimated using an HP filter (smoothing paramter $10^{5}$ ). See Figure 1 for data sources. Gray bars denote recessions. 
Figure 3: Measured Job Openings (JOLTS) and the Help-Wanted Index (HWI)

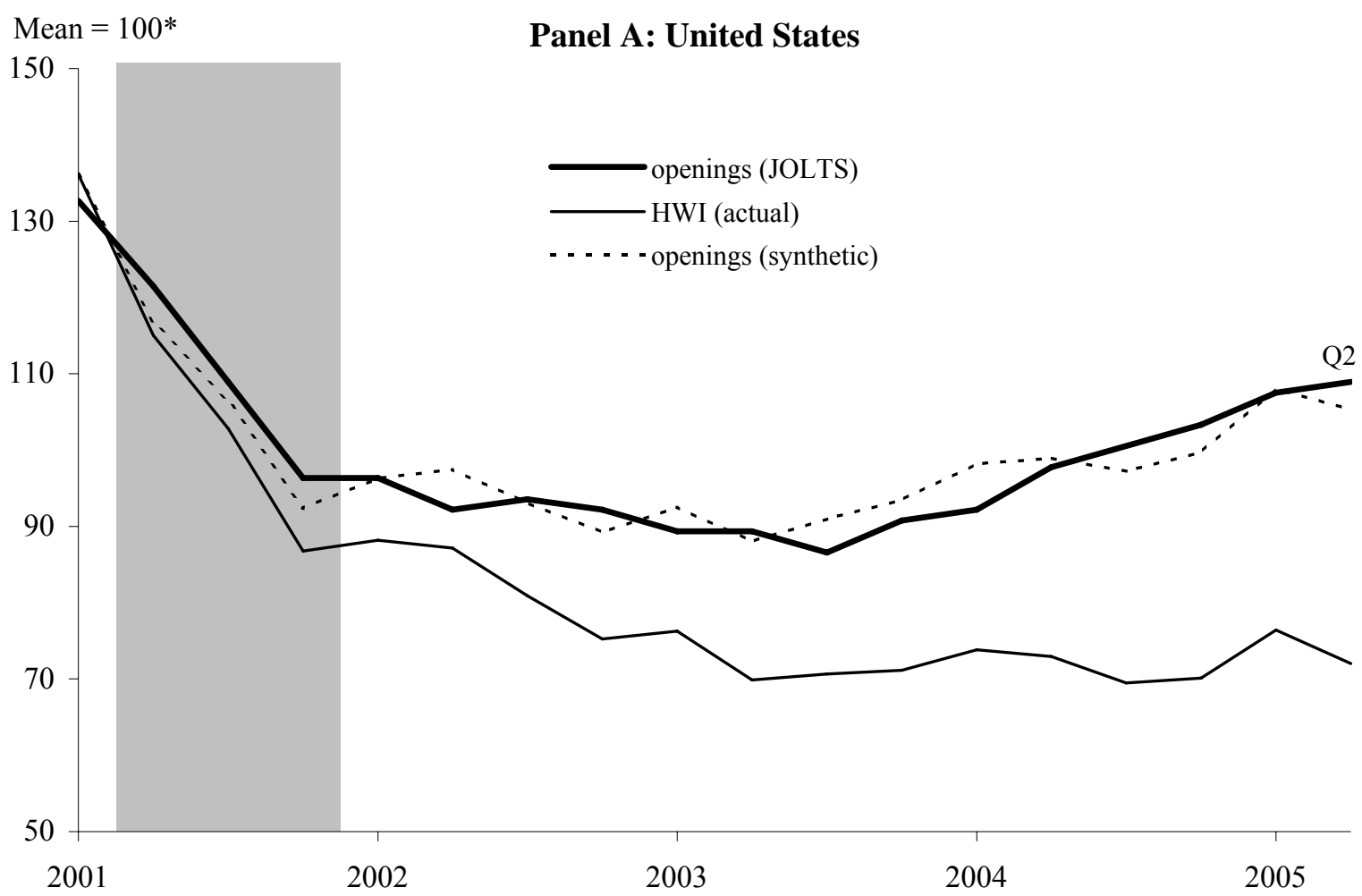

Note: Job openings data are from the U.S. BLS, Job Openings and Labor Turnover Survey (JOLTS); see Figure 1 for additional sources. The synthetic openings series is formed using an OLS regression fit of the JOLTS openings series to the normalized help-wanted index and a linear time trend (see text for details).

* The observed and synthetic job openings series are normalized so that their means equal 100; the HWI series is normalized to equal the synthetic openings series in 2001Q1. 
Figure 3 (continued)

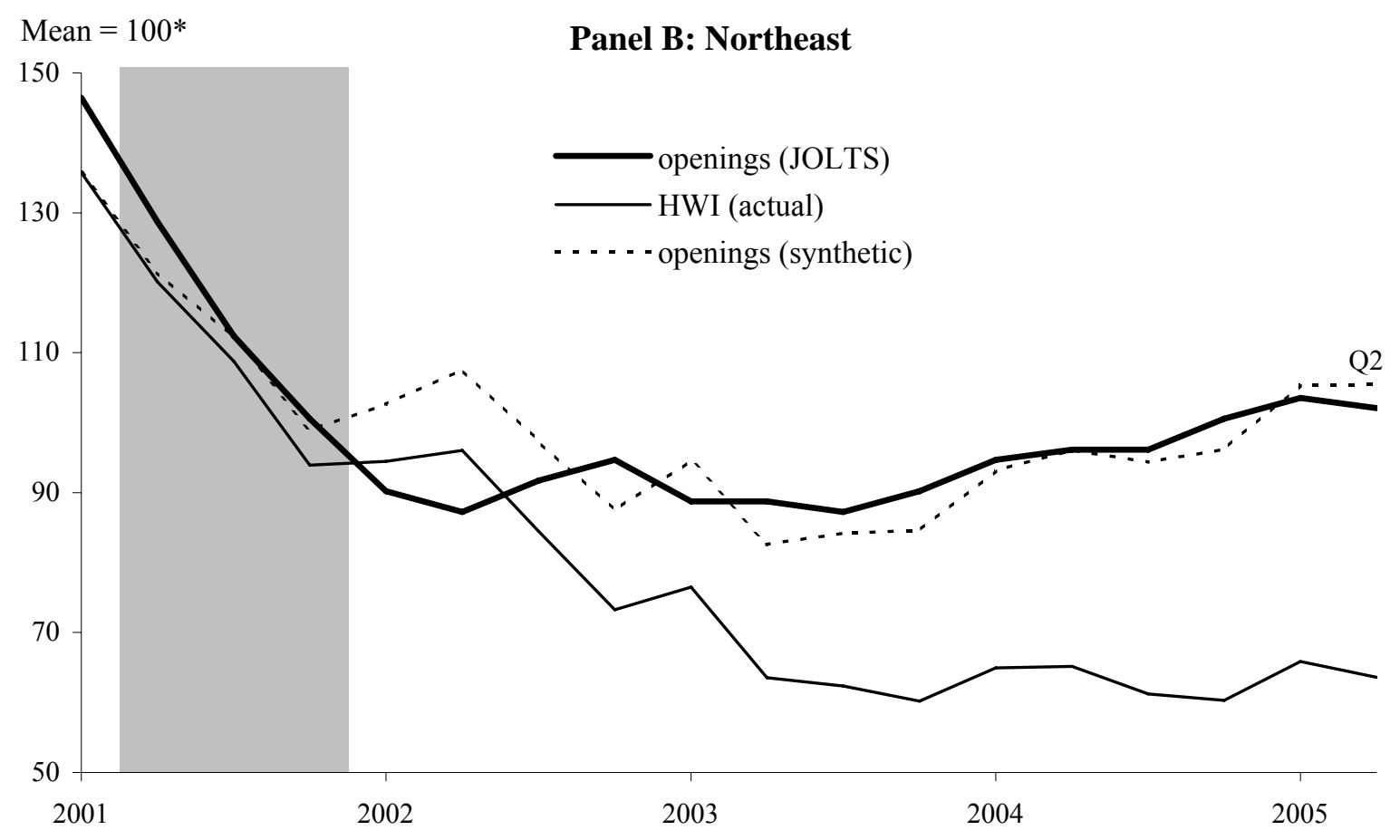

Mean $=100^{*}$

Panel C: Midwest

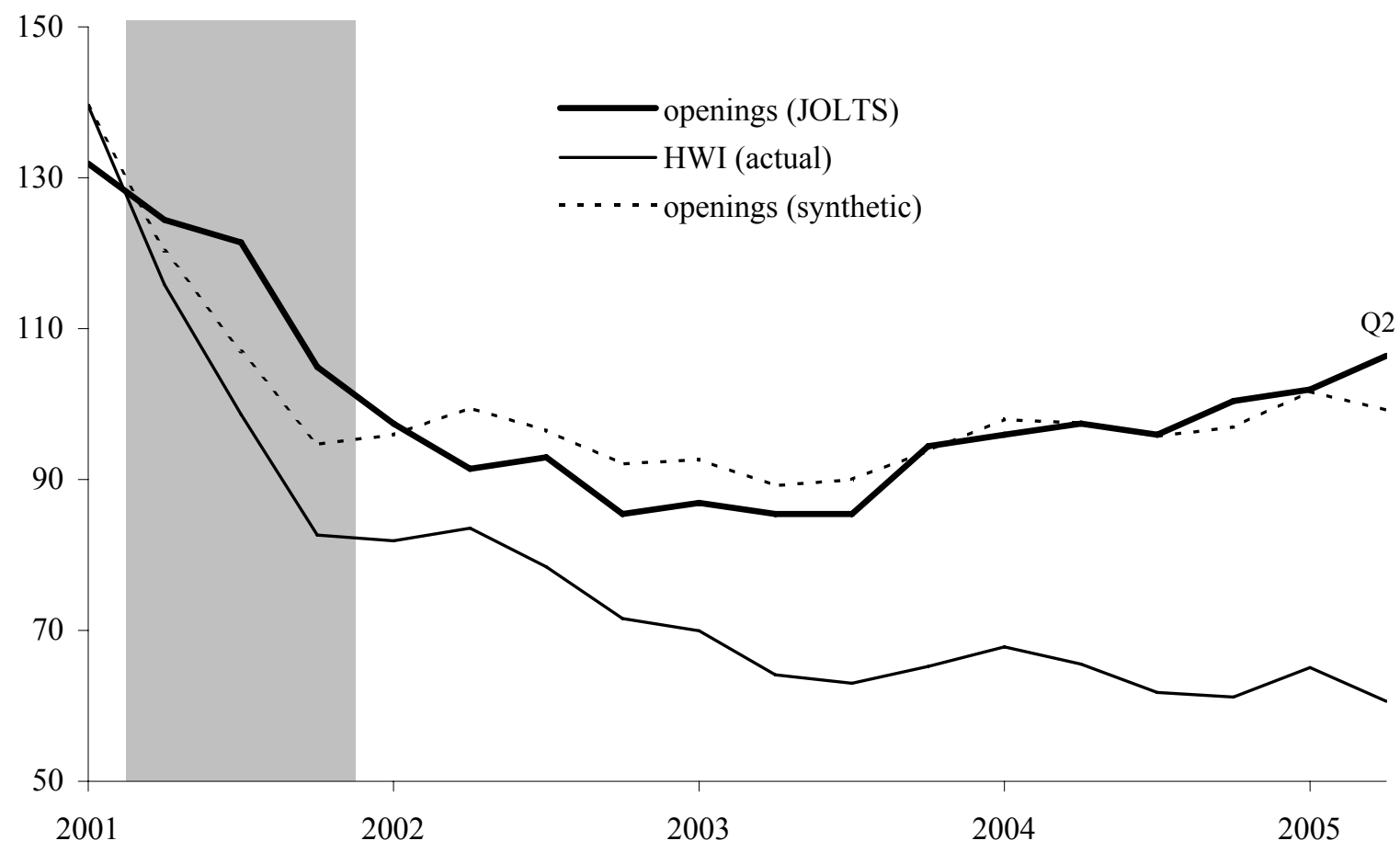

Note: Job openings data are from the U.S. BLS, Job Openings and Labor Turnover Survey (JOLTS); see Figure 1 for additional sources. The synthetic openings series is formed using an OLS regression fit of the JOLTS openings series to the normalized help-wanted index and a linear time trend (see text for details).

* The observed and synthetic job openings series are normalized so that their means equal 100; the HWI series is normalized to equal the synthetic openings series in $2001 \mathrm{Q} 1$. 
Figure 3 (continued)
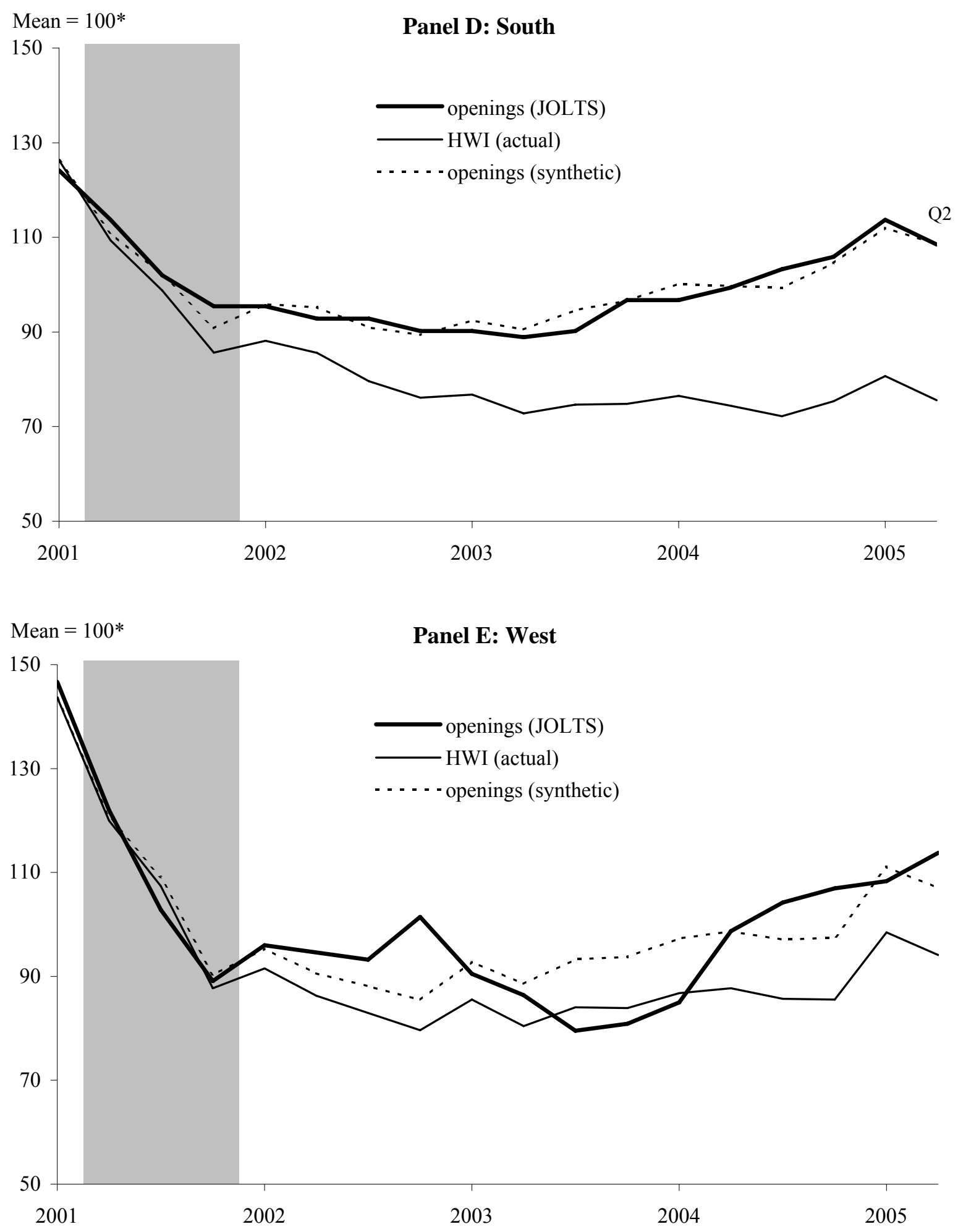

Note: Job openings data are from the U.S. BLS, Job Openings and Labor Turnover Survey (JOLTS); see Figure 1 for additional sources. The synthetic openings series is formed using an OLS regression fit of the JOLTS openings series to the normalized help-wanted index and a linear time trend (see text for details).

* The observed and synthetic job openings series are normalized so that their means equal 100; the HWI series is normalized to equal the synthetic openings series in $2001 \mathrm{Q} 1$. 
Figure 4: U.S. Synthetic Vacancy Rate, 1960-2005 (quarterly data)

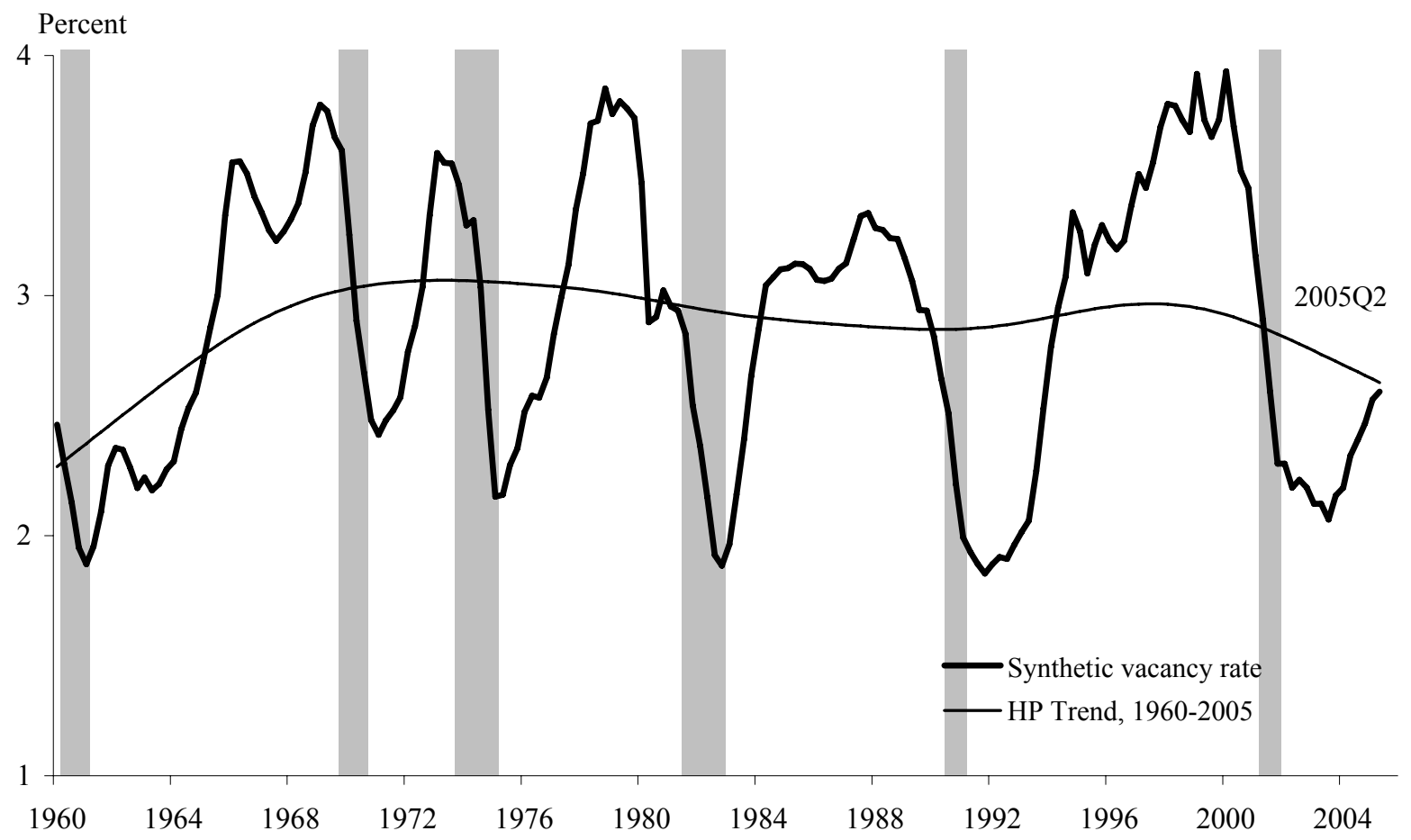

Note: See text for series description. Trend estimated using an HP filter (smoothing parameter $10^{5}$ ). Gray bars denote recessions. The underlying data are seasonally adjusted. 
Figure 5: Trends in the U.S. Unemployment Rate, 1960-2005 (quarterly data)

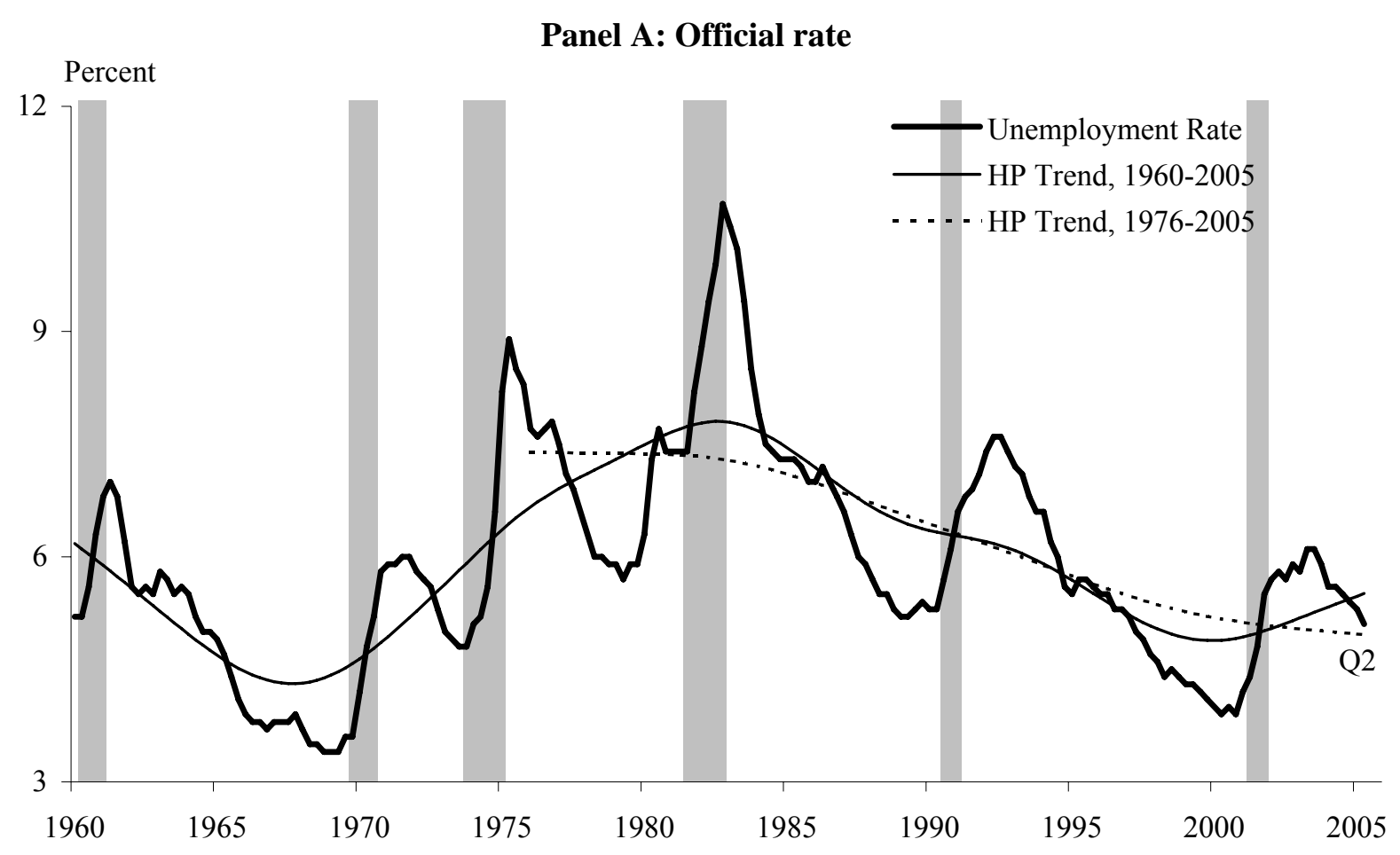

Panel B: Age-adjusted rate

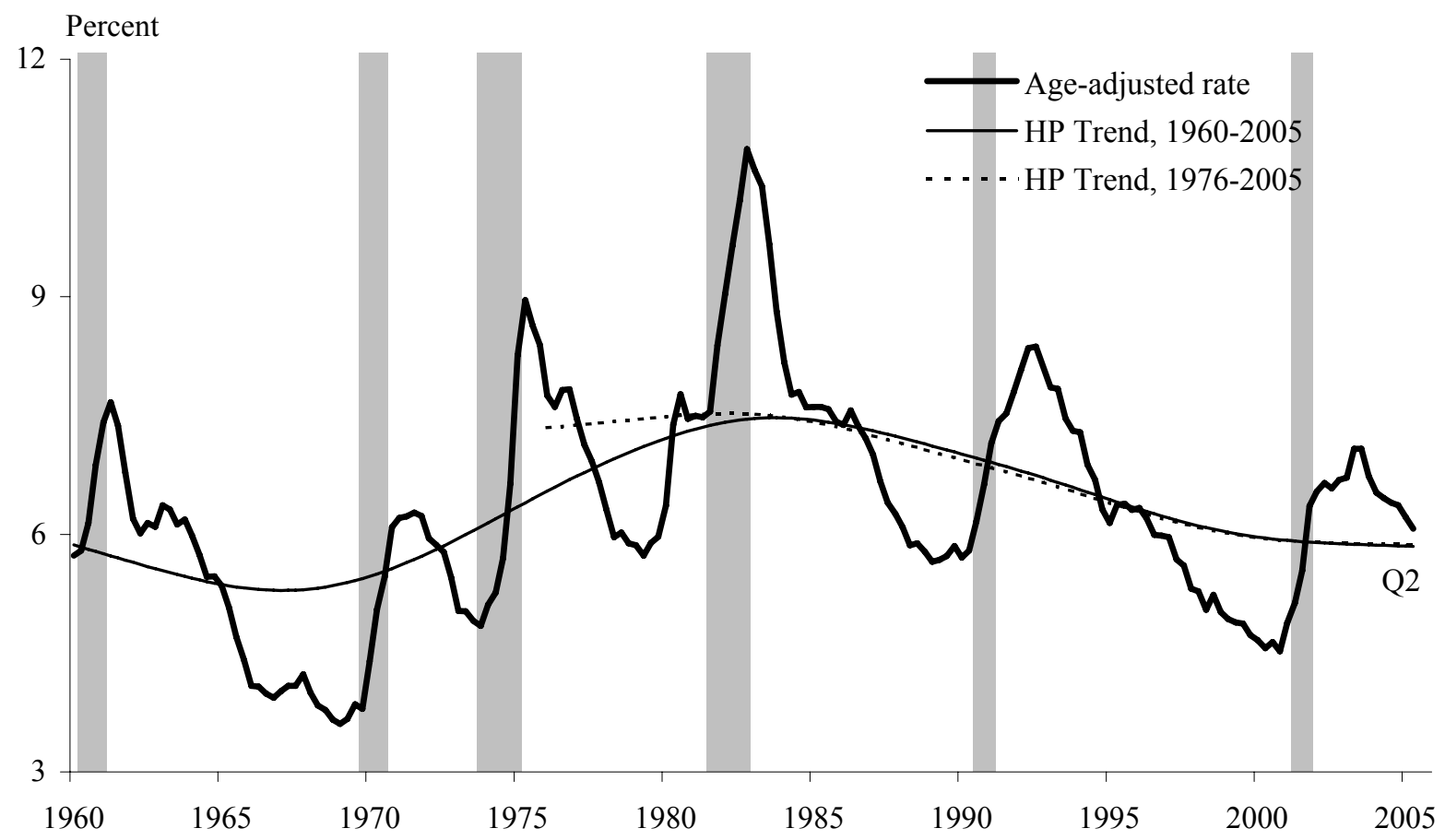

Note: Trend estimated using an HP filter (smoothing parameter $10^{5}$ ). See Figure 1 for data sources. Gray bars denote recessions. 
Figure 6: U.S. Beveridge Curve, Adjusted, 1960-2005

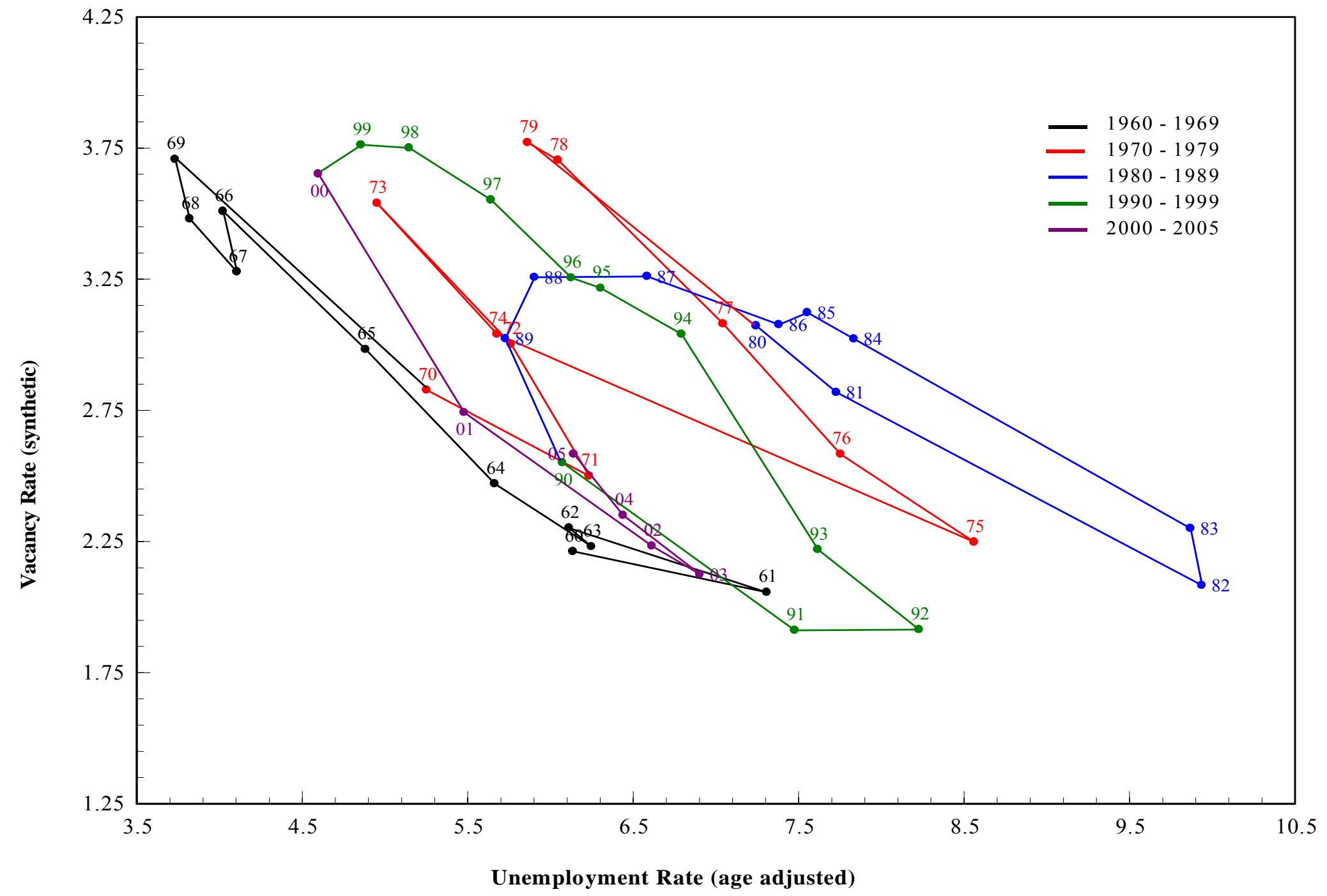

Note: The vacancy rate (synthetic) and unemployment rate (age adjusted) are based on the author's calculations; see the text for details. Data for 2005 are through Q2. The underlying data are seasonally adjusted. 
Figure 7: Beveridge Curve Shifts,

Cumulative (adjusted data), 1976-2005

(with and without regional dispersion)

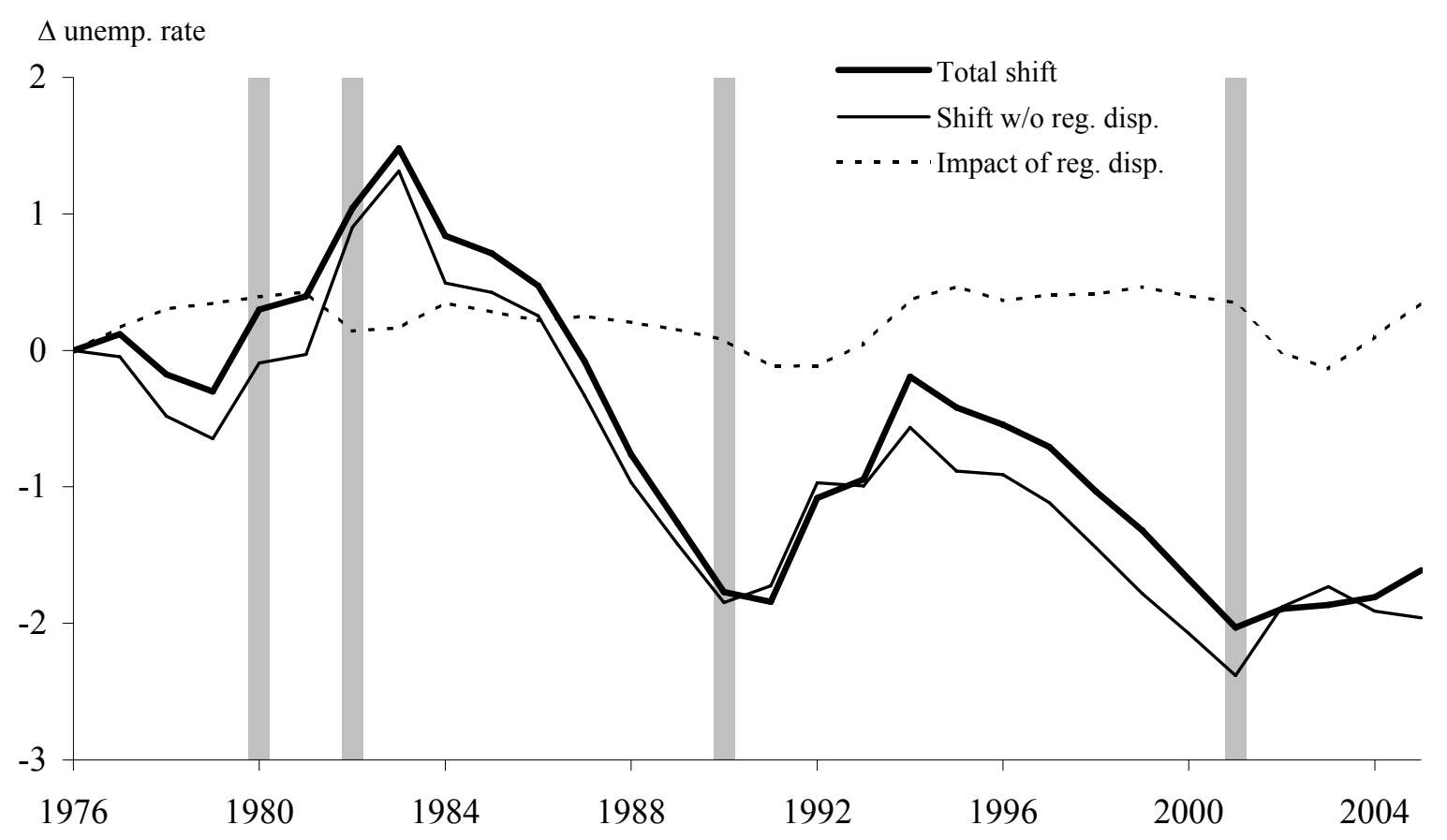

Note: Derived from the coefficients on the year dummies from the regressions in Table 2; see text for details. Data for 2005 are though Q2. 
Figure 8: Dispersion of Employment Growth

across States and Geographic Divisions (annual data)

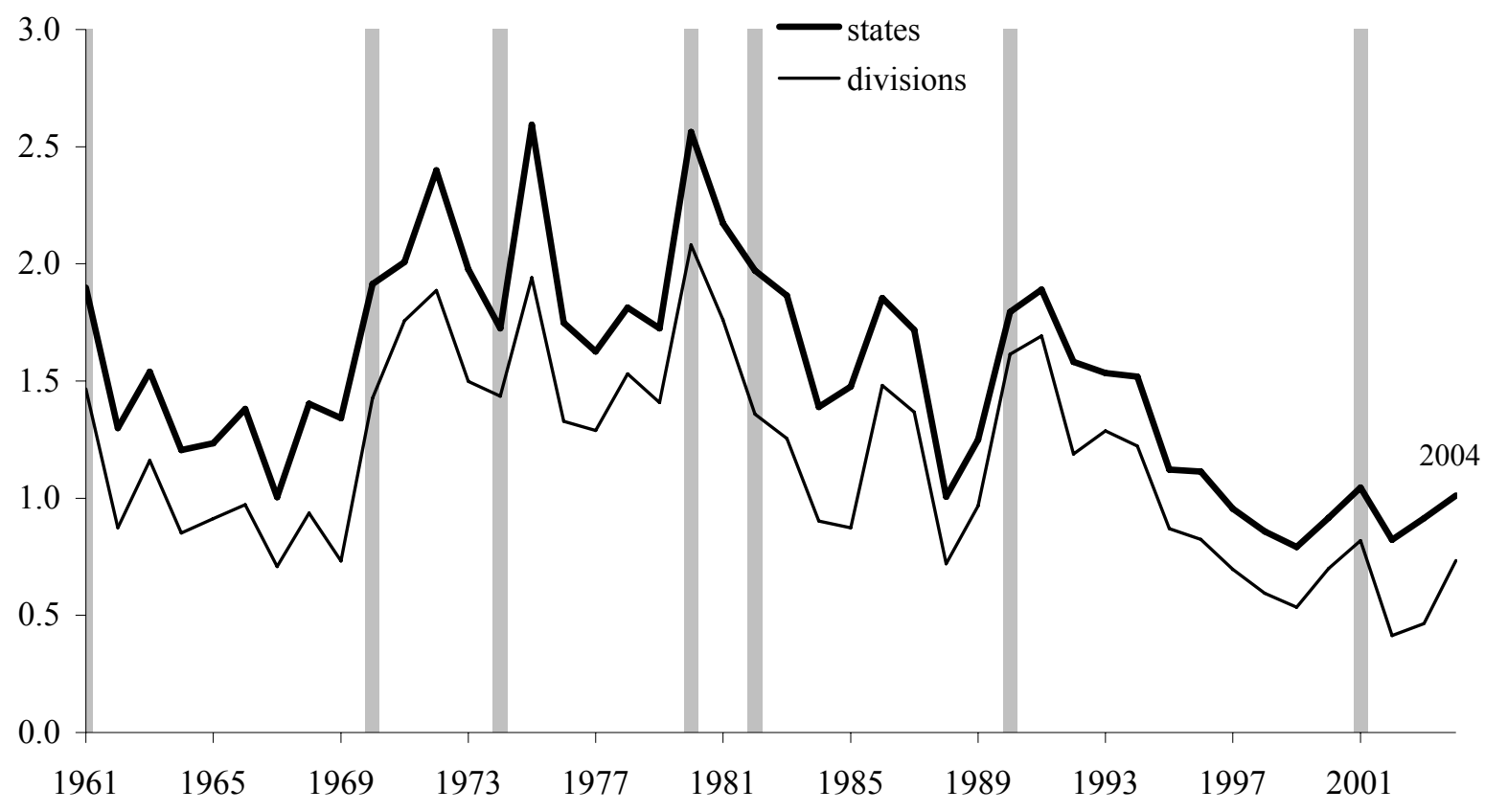

Note: See text for definition and calculation method. 
Table 1: Regression Results, JOLTS Vacancy Rate and the Normalized Help-Wanted Index (quarterly data, 2001Q1 - 2005Q2) Dependent Variable $=$ JOLTS vacancy rate

\begin{tabular}{|c|c|c|c|c|c|}
\hline & $\begin{array}{r}(1) \\
\text { U.S. }\end{array}$ & $\begin{array}{c}(2) \\
\text { Northeast } \\
\end{array}$ & $\begin{array}{c}(3) \\
\text { Midwest }\end{array}$ & $\begin{array}{c}(4) \\
\text { South } \\
\end{array}$ & $\begin{array}{c}(5) \\
\text { West } \\
\end{array}$ \\
\hline normalized HWI & $\begin{array}{c}6.22 * * \\
(0.507)\end{array}$ & $\begin{array}{l}6.53 * * \\
(1.10)\end{array}$ & $\begin{array}{c}4.47 * * \\
(0.681)\end{array}$ & $\begin{array}{c}6.92 * * \\
(0.461)\end{array}$ & $\begin{array}{l}6.88 * * \\
(1.03)\end{array}$ \\
\hline time trend & $\begin{array}{l}0.051 * * \\
(0.007)\end{array}$ & $\begin{array}{l}0.068 * * \\
(0.018)\end{array}$ & $\begin{array}{l}0.041 * * \\
(0.012)\end{array}$ & $\begin{array}{l}0.056^{* *} \\
(0.005)\end{array}$ & $\begin{array}{c}0.024 * \\
(0.011)\end{array}$ \\
\hline constant & $\begin{array}{l}-5.25 * * \\
(0.885)\end{array}$ & $\begin{array}{l}-7.24 * * \\
(2.32)\end{array}$ & $\begin{array}{l}-3.84 * * \\
(1.53)\end{array}$ & $\begin{array}{l}-5.83 * * \\
(0.658)\end{array}$ & $\begin{array}{l}-2.53 \\
(1.45)\end{array}$ \\
\hline $\mathrm{R}^{2}$ & 0.906 & 0.730 & 0.766 & 0.930 & 0.733 \\
\hline
\end{tabular}

Note: Standard errors listed in parentheses below the OLS regression coefficients.

** denotes significance at the $99 \%$ level

* denotes significance at the $95 \%$ level 
Table 2: Beveridge Curve Regressions, Adjusted Quarterly Data (with yearly shifts), 1976Q1-2005Q2

Dependent Variable $=$ age-adjusted unemployment rate

\begin{tabular}{|c|c|c|c|c|c|c|c|c|c|c|c|}
\hline & (1) & $\begin{array}{c}(2) \\
\text { Weighted }\end{array}$ & $\begin{array}{c}\text { (3) } \\
\text { New }\end{array}$ & $\begin{array}{l}\text { (4) } \\
\text { Mid }\end{array}$ & $\begin{array}{c}(5) \\
\text { East North }\end{array}$ & $\begin{array}{c}\text { (6) } \\
\text { West North }\end{array}$ & $\begin{array}{l}\text { (7) } \\
\text { South }\end{array}$ & $\begin{array}{c}(8) \\
\text { East South }\end{array}$ & $\begin{array}{c}\text { (9) } \\
\text { West South }\end{array}$ & (10) & (11) \\
\hline & U.S. & $\underline{\text { Sum }}$ & England & $\underline{\text { Atlantic }}$ & Central & Central & $\underline{\text { Atlantic }}$ & $\underline{\text { Central }}$ & $\underline{\text { Central }}$ & $\underline{\text { Mountain }}$ & $\underline{\text { Pacific }}$ \\
\hline vacancies & $\begin{array}{l}-4.72 * * \\
(0.620)\end{array}$ & -3.78 & $\begin{array}{l}-3.92 * * \\
(0.557)\end{array}$ & $\begin{array}{l}-4.44 * * \\
(0.709)\end{array}$ & $\begin{array}{l}-5.92 * * \\
(0.791)\end{array}$ & $\begin{array}{l}-3.49^{* *} \\
(0.471)\end{array}$ & $\begin{array}{l}-3.27 * * \\
(0.504)\end{array}$ & $\begin{array}{l}-3.94 * * \\
(0.645)\end{array}$ & $\begin{array}{l}-3.56^{* *} \\
(0.745)\end{array}$ & $\begin{array}{l}-2.37 * * \\
(0.374)\end{array}$ & $\begin{array}{l}-1.88^{* *} \\
(0.416)\end{array}$ \\
\hline (vacancies) $^{2}$ & $\begin{array}{c}0.533 * * \\
(0.109)\end{array}$ & 0.444 & $\begin{array}{l}0.613 * * \\
(0.130)\end{array}$ & $\begin{array}{l}0.633 * * \\
(0.147)\end{array}$ & $\begin{array}{l}0.775^{* *} \\
(0.159)\end{array}$ & $\begin{array}{l}0.448^{* *} \\
(0.084)\end{array}$ & $\begin{array}{l}0.361^{* *} \\
(0.085)\end{array}$ & $\begin{array}{l}0.384 * * \\
(0.084)\end{array}$ & $\begin{array}{l}0.360^{* *} \\
(0.108)\end{array}$ & $\begin{array}{l}0.149 * * \\
(0.042)\end{array}$ & $\begin{array}{c}0.083 \\
(0.049)\end{array}$ \\
\hline constant & $\begin{array}{l}16.40 * * \\
(0.899)\end{array}$ & 14.64 & $\begin{array}{l}12.67 * * \\
(0.479)\end{array}$ & $\begin{array}{l}15.42^{* *} \\
(0.820)\end{array}$ & $\begin{array}{l}17.20^{* *} \\
(1.03)\end{array}$ & $\begin{array}{l}10.87^{* *} \\
(0.676)\end{array}$ & $\begin{array}{l}13.64^{* *} \\
(0.765)\end{array}$ & $\begin{array}{l}14.80^{* *} \\
(1.24)\end{array}$ & $\begin{array}{l}13.57^{* *} \\
(1.29)\end{array}$ & $\begin{array}{l}14.58^{* *} \\
(0.889)\end{array}$ & $\begin{array}{l}15.27 * * \\
(0.909)\end{array}$ \\
\hline year dummies & yes & yes & yes & yes & yes & yes & yes & yes & yes & yes & yes \\
\hline $\mathrm{R}^{2}$ & 0.984 & & 0.974 & 0.972 & 0.986 & 0.975 & 0.976 & 0.977 & 0.976 & 0.948 & 0.976 \\
\hline
\end{tabular}

** denotes significance at the $99 \%$ level

* denotes significance at the $95 \%$ level

Note: Vacancies refers to the synthetic vacancy series formed as described in Section III. Standard errors are listed in parentheses below the OLS regression coefficients. Column 2 results are the weighted average of results from columns 3-11; see text Section IV. 


\section{Appendix Figure 1: Beveridge Curve Shifts, Cumulative (unadjusted data), 1976-2005 (with and without regional dispersion)}

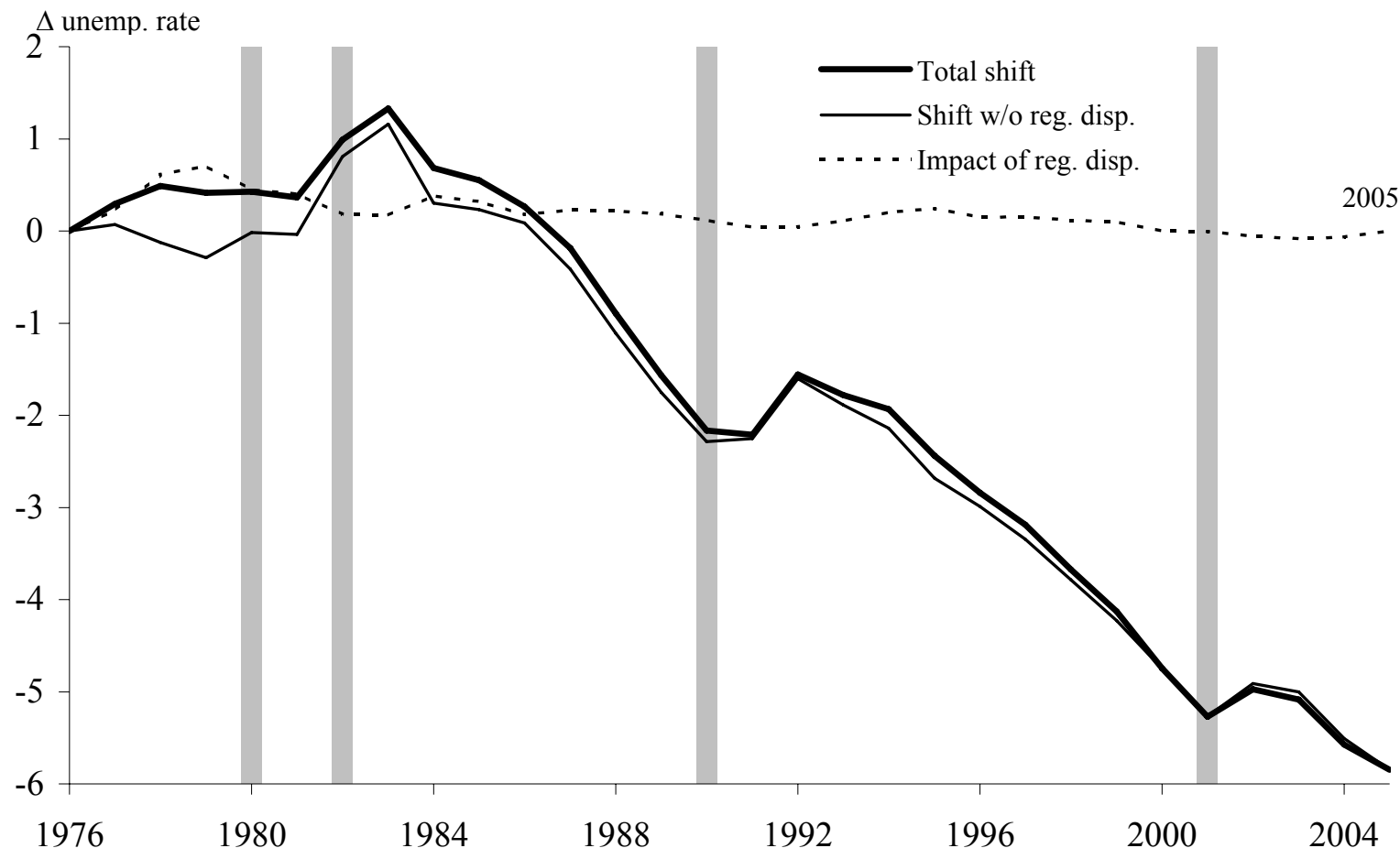

Note: Derived from the coefficients on the year dummies from the regressions in Appendix Table 1; see text for details. Data for 2005 are though Q2. 


\section{Appendix Table 1: Beveridge Curve Shifts and Regional Dispersion}

(cumulative; adjusted data)

(1)

$\begin{array}{lccc}\text { Year } & \text { Total Shift } & \begin{array}{c}\text { Shift w/o } \\ \text { reg. disp. }\end{array} & \begin{array}{c}\text { Impact of } \\ \text { reg. disp. }\end{array} \\ 1976 & 0.000 & 0.000 & 0.000 \\ 1977 & 0.119 & -0.048 & 0.167 \\ 1978 & -0.175 & -0.480 & 0.305 \\ 1979 & -0.301 & -0.647 & 0.346 \\ 1980 & 0.300 & -0.093 & 0.393 \\ 1981 & 0.396 & -0.031 & 0.427 \\ 1982 & 1.04 & 0.901 & 0.142 \\ 1983 & 1.48 & 1.32 & 0.165 \\ 1984 & 0.840 & 0.492 & 0.348 \\ 1985 & 0.709 & 0.426 & 0.283 \\ 1986 & 0.473 & 0.253 & 0.220 \\ 1987 & -0.081 & -0.332 & 0.251 \\ 1988 & -0.763 & -0.968 & 0.206 \\ 1989 & -1.26 & -1.42 & 0.154 \\ 1990 & -1.77 & -1.85 & 0.075 \\ 1991 & -1.84 & -1.73 & -0.116 \\ 1992 & -1.08 & -0.970 & -0.112 \\ 1993 & -0.945 & -0.994 & 0.049 \\ 1994 & -0.193 & -0.565 & 0.372 \\ 1995 & -0.418 & -0.885 & 0.467 \\ 1996 & -0.545 & -0.909 & 0.364 \\ 1997 & -0.708 & -1.12 & 0.409 \\ 1998 & -1.03 & -1.45 & 0.412 \\ 1999 & -1.32 & -1.78 & 0.464 \\ 2000 & -1.68 & -2.08 & 0.399 \\ 2001 & -2.03 & -2.38 & 0.352 \\ 2002 & -1.89 & -1.88 & -0.014 \\ 2003 & -1.86 & -1.73 & -0.134 \\ 2004 & -1.81 & -1.91 & 0.102 \\ 2005 & -1.61 & -1.96 & 0.349\end{array}$

Note: Table lists exact numbers used to construct Figure 7 in the text, derived from the results in Table 2; see text for details. 


\section{Appendix Table 2: Beveridge Curve Regressions, Unadjusted Quarterly Data (with yearly shifts)}

Dependent Variable $=$ unemployment rate

(1)

(2)

(3)

(4)

(5)

(6)

(7)

(8)

(10)

(11)

\begin{tabular}{|c|c|c|c|c|c|c|c|c|c|c|c|}
\hline & U.S. & $\begin{array}{c}\text { Weighted } \\
\text { Sum }\end{array}$ & $\begin{array}{c}\text { New } \\
\text { England }\end{array}$ & $\begin{array}{c}\text { Mid } \\
\text { Atlantic } \\
\end{array}$ & $\begin{array}{c}\text { East North } \\
\text { Central }\end{array}$ & $\begin{array}{c}\text { West North } \\
\text { Central }\end{array}$ & $\begin{array}{c}\text { South } \\
\text { Atlantic } \\
\end{array}$ & $\begin{array}{c}\text { East South } \\
\text { Central }\end{array}$ & $\begin{array}{c}\text { West South } \\
\text { Central }\end{array}$ & Mountain & $\underline{\text { Pacific }}$ \\
\hline Normalized HWI & $\begin{array}{l}-7.73 * * \\
(1.94)\end{array}$ & -8.73 & $\begin{array}{l}-9.31 * * \\
(2.09)\end{array}$ & $\begin{array}{l}-4.10 \\
(2.30)\end{array}$ & $\begin{array}{c}-10.77 * * \\
(1.94)\end{array}$ & $\begin{array}{l}-5.41 * * \\
(1.46)\end{array}$ & $\begin{array}{l}-7.63 * * \\
(1.57)\end{array}$ & $\begin{array}{c}-17.30 * * \\
(4.66)\end{array}$ & $\begin{array}{l}-8.93 * * \\
(2.49)\end{array}$ & $\begin{array}{c}-11.90 * * \\
(1.92)\end{array}$ & $\begin{array}{l}-9.11 * * \\
(1.95)\end{array}$ \\
\hline$\left(\right.$ Normalized HWI $^{2}$ & $\begin{array}{l}0.728 \\
(1.26)\end{array}$ & 2.02 & $\begin{array}{l}2.58^{* *} \\
(1.21)\end{array}$ & $\begin{array}{l}-1.22 \\
(1.50)\end{array}$ & $\begin{array}{l}2.41 * * \\
(1.19)\end{array}$ & $\begin{array}{l}1.12 \\
(0.904)\end{array}$ & $\begin{array}{c}2.05 * * \\
(0.923)\end{array}$ & $\begin{array}{l}8.01^{* *} \\
(3.28)\end{array}$ & $\begin{array}{c}2.63 \\
(1.58)\end{array}$ & $\begin{array}{l}3.69^{* *} \\
(1.17)\end{array}$ & $\begin{array}{c}1.71 \\
(1.18)\end{array}$ \\
\hline constant & $\begin{array}{l}13.26^{* *} \\
(0.795)\end{array}$ & 13.38 & $\begin{array}{l}14.63 * * \\
(0.936)\end{array}$ & $\begin{array}{c}13.85 * * \\
(0.967)\end{array}$ & $\begin{array}{l}14.94 * * \\
(0.884)\end{array}$ & $\begin{array}{c}8.82 * * \\
(0.643)\end{array}$ & $\begin{array}{l}12.14 * * \\
(0.707)\end{array}$ & $\begin{array}{l}14.70 * * \\
(1.12)\end{array}$ & $\begin{array}{l}11.07 * * \\
(1.01)\end{array}$ & $\begin{array}{l}14.19 * * \\
(0.842)\end{array}$ & $\begin{array}{c}15.04 * * \\
(0.837)\end{array}$ \\
\hline
\end{tabular}

year dummies

yes

yes

yes

yes

yes

yes

yes

yes

yes

yes

yes

$\mathrm{R}^{2}$

0.983

0.978

0.986

0.974

0.976

0.980

0.976

0.959

0.980

** denotes significance at the $99 \%$ level

* denotes significance at the $95 \%$ level

Note: Standard errors are listed in parentheses below the OLS regression coefficients. Column 2 results are the weighted average of results from columns 3-11; see text. 